\title{
PENGARUH METODE HYPNOTEACHING TERHADAP PRESTASI BELAJAR SISWA PADA BIDANG STUDI PAI DI SMP BINA BANGSA SURABAYA
}

\author{
Subiyono \& Nur Hamim \\ (Alumni IAIN Sunan Ampel Jurusan PAI) \\ (Dosen IAIN Sunan Ampel)
}

\begin{abstract}
Abstrak
Rumusan masalah dalam penelitian ini adalah: (1) Bagaimanakah penerapan metode hypnoteaching pada bidang studi pendidikan agama Islam di SMP Bina Bangsa Surabaya? (2) Bagaimanakah prestasi belajar siswa pada bidang pendidikan agama Islam di SMP Bina Bangsa Surabaya? (3) Adakah pengaruh metode hypnoteaching pada bidang studi pendidikan agama Islam terhadap prestasi belajar siswa di SMP Bina Bangsa?

Sampel penelitian adalah $10 \%$ dari 526 siswa yaitu 53 siswa, teknik pengambilan sampel adalah dengan teknik stratified proportional random sampling yaitu mengacak sampel pada setiap strata dengan pembagian yang sama. Teknik analisis data dalam penelitian ini adalah: (1) Rumus prosentase sederhana, yaitu untuk menganalisis data tentang penerapan metode hypnoteaching di SMP Bina Bangsa dan prestasi belajarnya pada bidang PAI; (2) Rumus Korelasi Product Moment, yaitu untuk menganalisis data tentang ada atau tidaknya pengaruh metode hypnoteaching terhadap prestasi belajar siswa pada bidang studi pendidikan agama Islam di SMP Bina Bangsa Surabaya.

Kesimpulan dari hasil penelitian ini adalah: (1) Penerapan strategi hypnoteaching di SMP Bina Bangsa Surabaya tergolong cukup. Hal ini terbukti dari hasil prosentase tertinggi ( $66 \%$ ) adalah berada pada interval $56 \%-75 \%$ yang berarti cukup; (2) Prestasi belajar siswa di SMP tergolong baik. Hal ini terbukti dari hasil rata-rata nilai ulangan siswa $(7,3)$ berada pada interval nilai $7-8$ yang berarti baik; (3) Terdapat pengaruh metode hypnoteaching terhadap prestasi belajar siswa di SMP Bina Bangsa Surabaya. Hal ini dibuktikan dari hasil perhitungan rumus $r_{x y}$ $(0,522)$ yang lebih besar dari hasil perhitungan tabel $\left(\mathrm{r}_{\mathrm{t}}\right)$ baik pada taraf signifikansi $5 \%(0,274)$ atau taraf signifikansi $1 \%(0,354)$ yang berarti Ha diterima dan Ho ditolak dan berarti terdapat pengaruh variabel $\mathrm{X}$ terhadap variabel $\mathrm{Y}$.
\end{abstract}

Kata Kunci: Hypnoteaching, Prestasi Belajar PAI dan SMP Binan Bangsa 


\section{A. Pendahuluan}

Proses belajar mengajar merupakan inti dari proses pendidikan secara keseluruhan dengan guru sebagai pemegang peran utama. Proses belajar mengajar juga merupakan proses yang mengandung serangkaian perbuatan guru dan siswa atas dasar hubungan timbal balik yang berlangsung dalam suasana edukatif untuk mencapai tujuan. Interaksi atau hubungan timbal balik antara guru dan siswa merupakan syarat utama bagi berlangsungnya proses belajar mengajar. ${ }^{1}$

Dalam Undang-undang RI. No. 20 tahun 2003 tentang Sistem Pendidikan Nasional BAB II pasal 3 di jelaskan bahwa :

"Pendidikan nasional berfungsi mengembangkan kemampuan dan membentuk watak serta peradaban bangsa, bertujuan untuk mengembangkan potensi peserta didik agar menjadi manusia yang beriman dan bertaqwa kepada Tuhan Yang Maha Esa, berakhlaq mulia, sehat, berilmu, cakap, kreatif, mandiri, dan menjadi warga negara yang demokratis serta bertanggung jawab ${ }^{2}$

Untuk merealisasikan tujuan pendidikan nasional diatas peranan guru sebagai pendidik sangat dibutuhkan, karena guru adalah pihak yang langsung terjun di lapangan untuk mendidik dan membimbing siswa atau peserta didik, demi mencapai keberhasilan proses pembelajaran dan demi mencapai tujuan pengajaran serta tujuan pendidikan yang telah ditetapkan. Guru sebagai pendidik harus mampu untuk menciptakan interaksi yang baik dengan siswa, sebab peranan guru sangat dibutuhkan dalam perubahan tingkah laku yang mencakup tiga aspek yaitu aspek kognitif, aspek afektif, dan aspek psikomotorik.

Selanjutnya, membimbing mereka agar upaya belajarnya terarah, berlangsung lancar dan berhasil, upaya yang demikian itu adalah upaya pembelajaran ${ }^{3}$. Tugasnya seorang guru berusaha untuk

\footnotetext{
${ }^{1}$ M. Uzer Ustman, Menjadi Guru Profesional, (Bandung: Remaja Rosda Karya, 1995), 1

${ }^{2}$ UU RI No. 21, Tentang Sistem Pendidikan Nasional, (Bandung: Citra Umbara, 2003), 76

${ }^{3}$ Yusuf Hadi Miarso, dkk. Teknologi Komunikasi Pendidikan, (Jakarta: Rajawali, 1986), 32
} 
membelajarkan siswa yang tentunya disesuaikan dengan tujuan pendidikan agama Islam itu sendiri. Upaya pembelajaran itu agar berhasil hendaklah dilaksanakan secara sistematis (secara kuat dengan mempertimbangkan segala dampaknya) dengan kata lain kegiatan belajar dan upaya pembelajaran harus di pandang sebagai suatu sistem yaitu sistem pembelajaran.

Suatu lembaga pendidikan harus memberikan sistem pembelajaran yang sesuai dengan kebutuhan siswa. Banyak sekali konsep-konsep pembelajaran yang ditawarkan dengan metode yang beranekaragam untuk keberhasilan suatu pendidikan, dapat dikatakan berhasil tidaknya atau efektif tidaknya suatu pembelajaran pada dasarnya adalah tergantung pada sistem pembelajaran. ${ }^{4}$

Produk pendidikan ditentukan oleh proses, secara operasional bahwa proses pendidikan yang baik dan benar akan menghasilkan produk yang baik pula. Dari pernyataan tersebut menunjukkan bahwa sistem pembelajaran itu sangat penting dalam pelaksanaan proses belajar mengajar. Maka diharapkan seorang guru dapat menjalankan sistem pembelajaran PAI yang sesuai dengan tujuan yang hendak dicapai yaitu membimbing siswa agar dapat meyakini dan mengamalkan ajaran Islam serta sebagai pandangan hidup. ${ }^{5}$ Komponenkomponen yang terkandung dalam sistem pembelajaran pendidikan agama Islam adalah sebagai berikut: tujuan pembelajaran pendidikan agama Islam, bahan/materi, kegiatan belajar mengajar, metode pengajaran alat bantu (saran) dan sumber pelajaran serta evaluasi. ${ }^{6}$

Mempelajari sebuah mata pelajaran mestinya untuk mendapatkan hasil pengajaran yang autentik yang merupakan pengalaman yang mengilhami dan menantang. Itu adalah suatu pengalaman yang membangkitkan berbagai jenis sifat, sikap dan disposisi yang diinginkan, serta yang konstriktif. Cara mempelajari mata pelajaran dengan wajar merupakan suatu proses penemuan, pemikiran kreatif, yang mengajak bersikap kooperatif, merupakan proses mencapai

${ }^{4}$ Oemar Hamalik. Kurikulum dan Pembelajaran. ( Jakarta: Bumi Aksara, 2003 ), 7

${ }^{5}$ Zakiah Drajat dkk, Ilmu Pengetahuan Pendidikan Islam, (Jakarta: Bumi Aksara, 2000), 86

${ }^{6}$ Syaiful Bahri Djamarah, Strategi belajaran Mengajar, (Jakarta: Rineka Cipta, 2002), 48 
prestasi yang berarti dan untuk merealisasi tenaga-tenaga pengajar yang profesional. Ia merupakan suatu proses, yang dalam dan dirinya memupuk dan menguntungkan perkembangan kepribadian pelajar. Akan tetapi bila mempelajari mata pelajaran dilakukan dengan cara-cara rutin yang menjemukan, maka proses itu menjadi gersang bagi nilai kepribadian. $^{7}$

Michael Pressley menyatakan bahwa strategi-strategi belajar adalah sebagai berikut:

"Operator-operator kognitif meliputi terdiri atas proses-proses yang secara langsung terlibat dalam menyelesaikan suatu tugas (belajar). Strategi-strategi tersebut merupakan strategi-strategi yang digunakan siswa untuk memecahkan masalah belajar tertentu. Untuk menyelesaikan tugas belajar siswa memerlukan keterlibatan dalam proses-proses berpikir dan perilaku, menskim atau membaca sepintas lalu judul-judul utama, meringkas, dan membuat catatan, di samping itu juga memonitor jalan berpikir diri sendiri". ${ }^{8}$

Guru dituntut untuk menguasai bermacam metode pembelajaran yang sesuai dengan karakteristik materi dan siswa. Dalam memilih metode, kadar keaktifan siswa harus selalu diupayakan tercipta dan berjalan terus dengan menggunakan beragam metode. Keaktifan siswa di kelas sangat diperlukan karena proses kerja sistem memori sangat membantu perkembangan emosional siswa. Dalam Islam, penekanan proses kerja sistem memori terhadap signifikansi fungsi kognitif (aspek aqliah) dan fungsi sensori (indera-indera) sebagai alat-alat penting untuk belajar, sangat jelas. Dan Al-Qur'an bukti betapa pentingnya penggunaan fungsi ranah cipta dan karsa manusia dalam belajar dan meraih ilmu pengetahuan.

Allah berfirman dalam Al-Isra' ayat 36 yang artinya: "Dan janganlah kamu membiasakan diri pada apa yang kamu tidak ketahui,

\footnotetext{
${ }^{7}$ James. L, Murseli, Pengajaran Berhasil, (Jakarta: Yayasan Penerbit Universitas Indonesia, 1975), 6

${ }^{8}$ Trianto, Model-model Pembelajaran Inovatif Berorientasi Konstrutivistik, (Jakarta: Prestasi Pustaka Publisher, 2007), 85
} 
karena sesungguhnya pendengaran, penglihatan dan daya nalar pasti akan ditanya mengenai itu" (Q.S Al-Isra': 36). ${ }^{9}$

Perintah belajar di atas, tentu saja harus dilaksanakan melalui proses kognitif (tahapan-tahapan yang bersifat aqliah). Dalam hal ini, sistem memori yang terdiri atas memori sensori, memori jangka pendek, dan memori jangka panjang berperan sangat aktif dan menentukan berhasil atau gagalnya seseorang dalam meraih pengetahuan dan keterampilan. ${ }^{10}$ Dengan motivasi yang tinggi, siswa dapat memecahkan masalahnya sendiri, yang paling penting siswa melakukan kegiatan belajar penuh kesadaran dan konsentrasi tinggi.

Salah satu alternatif yang dapat dilakukan oleh seorang guru guna lebih mengaktifkan belajar siswa di kelas yaitu dengan menggunakan metode Hypnoteaching. Metode ini dapat diterapkan pada pembelajaran untuk membuat anak lebih termotivasi dan lebih fokus pada pembelajaran. ${ }^{11}$ Dengan metode Hypnoteaching, siswa akan mengikuti intruksi guru dengan suka rela dan senang hati. Karena setiap siswa merasa termotivasi dengan sesuatu yang dikerjakannya.

\section{B. Rumusan Masalah}

1. Bagaimanakah pelaksanaan metode Hypnoteaching dalam pembelajaran PAI di SMP Bina Bangsa Surabaya?

2. Bagaimanakah prestasi belajar siswa pada bidang studi PAI di SMP Bina Bangsa Surabaya?

3. Adakah pengaruh metode Hypnoteaching terhadap prestasi belajar siswa pada bidang studi PAI di SMP Bina Bangsa Surabaya?

\section{Metode Penelitian}

Jenis penelitian jika dilihat dari judul penelitian yang digunakan penulis dalam penelitian ini adalah Penelitian Korelasional berjenis kausal. Penelitian Korelasional adalah penelitian yang bertujuan mencari

\footnotetext{
${ }^{9}$ Departemen Agama RI, Al-Aliyy, Al-Qur'an dan Terjemahannya, (Bandung: CV Penerbit Diponegoro, 2000), 228

${ }^{10}$ Muhibbin Syah, Psikologi Belajar (Jakarta: RajaGrafindo Persada,2004), 86

${ }^{11}$ Ibnu Hajar, M.Pd., Hypnoteaching Memaksimalkan Hasil Proses Belajarmengajar dengan Hypnoterapi, (Jojakarta: Diva Press, 2011), 36 
hubungan antara dua fenomena atau lebih. ${ }^{12}$ Sedangkan Kausal adalah hubungan yang bersifat sebab akibat, dimana ada Variabel Independen (variabel yang mempengaruhi) sebagai variabel $\mathrm{X}$ dan Variabel Dependen (variabel yang dipengaruhi) sebagai variabel $Y^{13}$

Jika dilihat dari analisis data maka penelitian ini berjenis penelitian kuantitatif karena data dianalisis dengan menggunakan rumus statistik product moment. Dan berdasarkan sumbernya jenis data dapat digolongkan menjadi dua yaitu data primer dan data sekunder. Yang dimaksud dengan sumber data dalam penelitian ini adalah subjek dari mana data dapat diperoleh. ${ }^{14}$

Populasi dalam penelitian ini adalah seluruh siswa SMP Bina Bangsa Surabaya yang berjumlah 526 siswa, yaitu meliputi siswa kelas VII ( A - E ), kelas VIII ( A - E ) dan kelas IX ( A - E ). Adapun jumlah sampel dalam penelitian ini adalah $10 \%$ dari populasi ( 526 siswa), yaitu 53 siswa, dengan perincian sebagai berikut :

\begin{tabular}{lccc} 
Kelas VII ( A - E ) & $: 198$ anak & $10 \%=20$ anak \\
Kelas VIII ( A - E ) & $: 175$ anak & $10 \%=18$ anak \\
Kelas IX ( A - E ) & $: 153$ anak & $10 \%=15$ anak \\
\hline Jumlah & 526 anak & 53 anak
\end{tabular}$+$

Cara yang dipakai dalam pengambilan sampel di atas adalah dengan Random Sampling (mengacak sampel) dengan teknik Stratifield Proportionate Random Sampling, yaitu mengacak sample pada tiap strata dengan pembagian yang sama. Metode pengumpulan data dalam penelitian ini adalah: Angket, Interview, Dokumentasi, Observasi. Setelah data terkumpul, maka dianalisis dengan Product Moment.

\footnotetext{
${ }^{12}$ Suharsimi Arikunto. Prosedur Penelitian Suatu Pendekatan Praktik (Edisi Revisi VI . ( Jakarta: Rineka Cipta, 2006), 36

${ }^{13}$ Anas Sujiono. Pengantar Sttistik Pendidikan, (Jakarta : PT. Raja Grafindo Persada, 2008), 59

${ }^{14}$ Suharsimi Arikunto, Prosedur Penelitian, (Jakarta: PT Rineka Cipta, 2002), 106
} 


\section{Hasil Penelitian}

\section{Penerapan Metode Hypnoteaching}

Penerapan metode hypnoteaching di SMP Bina Bangsa Surabaya dilakukan dengan cara setiap megawali pelajaran guru mengajak siswa untuk melakukan rilesasi, memberika sugesti dengan kata-kata motivasi, visualisasi, afirmasi, dan yel-yel untuk penyemangat. Untuk menghitung data tentang penerapan metode hypnoteaching adalah diambil dari angket yang telah disebarkan pada 53 sampel penelitian, dengan rincian sebagai berikut:

Guru berpenampilan menarik dan meyakinkan

\begin{tabular}{|c|l|c|c|c|}
\hline No & Alternatif Jawaban & N & F & \% \\
\hline \multirow{3}{*}{1} & (a) Ya & & 23 & $43,3 \%$ \\
& (b) Kadang-kadang & 53 & 27 & $51,0 \%$ \\
& (c) Tidak & & 3 & $5,7 \%$ \\
\hline \multicolumn{2}{|c|}{ Jumlah } & 53 & 53 & $100 \%$ \\
\hline
\end{tabular}

Dari tabel di atas dapat di ketahui bahwa tentang guru berpenampilan menarik dan meyakinkan sebagai seorang guru adalah tergolong cukup atau sedang, terbukti 51,0\% menjawab kadangkadang ,kemudian baru 43,3\% menjawab ya, dan 5,7\% menjawab tidak.

Guru bersikap simpati dan tidak menyalahkan siswa

\begin{tabular}{|c|l|c|c|c|}
\hline No & Alternatif Jawaban & N & F & \% \\
\hline \multirow{3}{*}{2} & (a) Ya & & 24 & $45,2 \%$ \\
& (b) Kadang-kadang & 53 & 25 & $47,2 \%$ \\
& (c) Tidak & & 4 & $7,6 \%$ \\
\hline \multicolumn{2}{|c|}{ Jumlah } & 53 & 53 & $100 \%$ \\
\hline
\end{tabular}

Dari tabel diatas dapat diketahui bahwa tentang guru bersikap simpati (memberikan perhatian dan tidak menyalahkan) kepada siswa adalah tergolong cukup atau sedang, terbukti 47,2 \% menjawab kadang-kadang, kemudian baru 45,2\% menjawab ya, dan $7.6 \%$ menjawab tidak. 
Guru menggunakan bahasa yang mudah dipahami dan mudah diingat

\begin{tabular}{|c|l|c|c|c|}
\hline No & Alternatif Jawaban & N & F & \% \\
\hline \multirow{3}{*}{3} & (a) Ya & & 25 & $47,2 \%$ \\
& (b) Kadang-kadang & 53 & 26 & $49,0 \%$ \\
& (c) Tidak & & 2 & $3,8 \%$ \\
\hline \multicolumn{2}{|c|}{ Jumlah } & 53 & 53 & $100 \%$ \\
\hline
\end{tabular}

Dari tabel diatas dapat diketahui bahwa tentang menggunakan bahasa yang mudah dipahami oleh siswa dan mudah diingat (berkesan) adalah cukup atau sedang, terbukti 49,0 \% menjawab kadang-kadang, kemudian baru 47,2 \% menjawab ya, dan 3,8\% menjawab tidak.

Guru memotivasi siswa dengan cerita orang-orang sukses

\begin{tabular}{|c|l|c|c|c|}
\hline No & Alternatif Jawaban & N & F & \% \\
\hline \multirow{3}{*}{4} & (a) Ya & & 22 & $41,5 \%$ \\
& (b) Kadang-kadang & 53 & 28 & $52,9 \%$ \\
& c) Tidak & & 3 & $5,6 \%$ \\
\hline \multicolumn{2}{|c|}{ Jumlah } & 53 & 53 & $100 \%$ \\
\hline
\end{tabular}

Dari tabel diatas dapat diketahui bahwa tentang guru memotivasi siswa dengan cerita orang-orang sukses adalah tergolong cukup atau sedang, terbukti 52,9 \% menjawab kadang - kadang, kemudian baru 41,5\% menjawab ya, dan 5,6\% menjawab tidak.

Guru dapat menguasai hati siswa (siswa tertarik karena merasa cocok)

\begin{tabular}{|c|l|c|c|c|}
\hline No & Alternatif Jawaban & N & F & \% \\
\hline \multirow{3}{*}{5} & (a) Ya & & 27 & $51,0 \%$ \\
& (b) Kadang-kadang & 53 & 24 & $45,2 \%$ \\
& (c) Tidak & & 2 & $3,8 \%$ \\
\hline \multicolumn{2}{|c|}{ Jumlah } & 53 & 53 & $100 \%$ \\
\hline
\end{tabular}


Dari tabel diatas dapat diketahui bahwa tentang guru dapat menguasai hati siswa (siswa tertarik karena merasa cocok) adalah tergolong baik, terbukti $51.0 \%$ menjawab ya, kemudian baru 45,2 \% menjawab kadang-kadang, dan 3,8 \% menjawab tidak.

Guru menyuruh siswa untuk melakukan afirmasi

\begin{tabular}{|c|l|c|c|c|}
\hline No & Alternatif Jawaban & N & F & \% \\
\hline \multirow{3}{*}{6} & (a) Ya & & 23 & $43,3 \%$ \\
& (b) Kadang-kadang & 53 & 27 & $51,0 \%$ \\
& (c) Tidak & & 3 & $5,7 \%$ \\
\hline \multicolumn{2}{|c|}{ Jumlah } & 53 & 53 & $100 \%$ \\
\hline
\end{tabular}

Dari tabel diatas dapat diketahui bahwa tentang menyuruh siswa untuk melakukan afirmasi adalah tergolong cukup atau sedang, terbukti $51.0 \%$ menjawab kadang - kadang, kemudian baru 43,3\% menjawab ya dan 5,7 \% menjawab tidak.

Guru menyuruh siswa untuk melakukan visualisasi

\begin{tabular}{|c|l|c|c|c|}
\hline No & Alternatif Jawaban & N & F & \% \\
\hline \multirow{3}{*}{7} & (a) Ya & & 24 & $45,2 \%$ \\
& (b) Kadang-kadang & 53 & 25 & $47,2 \%$ \\
& (c) Tidak & & 4 & $7,6 \%$ \\
\hline \multicolumn{2}{|c|}{ Jumlah } & 53 & 53 & $100 \%$ \\
\hline
\end{tabular}

Dari tabel diatas dapat diketahui bahwa tentang guru menyuruh siswa untuk melakukan visualisasi adalah tergolong cukup atau sedang, terbukti 47,2 \% menjawab kadang - kadang, kemudian baru $45,2 \%$ menjawab ya, dan 7,6 \% tidak.

Kondisi ruang kelas siswa terasa nyaman

\begin{tabular}{|c|l|c|c|c|}
\hline No & Alternatif Jawaban & N & F & \% \\
\hline \multirow{3}{*}{8} & (a) Ya & & 23 & $43,3 \%$ \\
& (b) Kadang-kadang & 53 & 28 & $52,9 \%$ \\
& (c) Tidak & & 2 & $3,8 \%$ \\
\hline \multicolumn{2}{|r|}{ Jumlah } & 53 & 53 & $100 \%$ \\
\hline
\end{tabular}


Dari tabel diatas dapat diketahui bahwa tentang kondisi ruang kelas siswa terasa nyaman adalah tergolong sedang atau cukup, terbukti 52,9 \% menjawab kadang-kadang, kemudian baru 43,3\% menjawab ya, dan $3,8 \%$ menjawab tidak.

Guru dapat memahami dan menyamakan pikiran siswa

\begin{tabular}{|c|l|c|c|c|}
\hline No & Alternatif Jawaban & N & F & \% \\
\hline \multirow{3}{*}{9} & (a) Ya & & 29 & $54,8 \%$ \\
& (b) Kadang-kadang & 53 & 23 & $43,3 \%$ \\
& (c) Tidak pernah & & 1 & $1,9 \%$ \\
\hline \multicolumn{2}{|c|}{ Jumlah } & 53 & 53 & $100 \%$ \\
\hline
\end{tabular}

Dari tabel diatas dapat diketahui bahwa tentang guru dapat memahami dan menyamakan dunia siswa (pikiran siswa) adalah tergolong baik, terbukti 54,8 \% menjawab ya, kemudian baru 43,3\% menjawab kadang-kadang,dan 1,9\% menjawab tidak.

Guru memutar musik slow (lembut) waktu mengajar

\begin{tabular}{|c|l|c|c|c|}
\hline No & Alternatif Jawaban & N & F & \% \\
\hline \multirow{3}{*}{10} & (a) Ya & & 27 & $51,0 \%$ \\
& (b) Kadang-kadang & 53 & 24 & $45,2 \%$ \\
& (c) Tidak & & 2 & $3,8 \%$ \\
\hline \multicolumn{2}{|c|}{ Jumlah } & 53 & 53 & $100 \%$ \\
\hline
\end{tabular}

Dari tabel diatas dapat diketahui bahwa tentang guru memutar musik slow (lembut) pada waktu mengajar adalah tergolong baik, terbukti 51,0\% menjawab ya, kemudian baru 45,2\% menjawab kadang-kadang dan 3,8\% menjawab tidak.

Guru memulai pelajaran dengan menyuruh siswa duduk santai

\begin{tabular}{|c|c|c|c|c|}
\hline No & Alternatif Jawaban & $\mathbf{N}$ & $\mathbf{F}$ & $\%$ \\
\hline \multirow{3}{*}{11} & (a) $\mathrm{Ya}$ & \multirow{3}{*}{53} & 21 & $39,7 \%$ \\
\hline & (b) Kadang-kadang & & 27 & $51,0 \%$ \\
\hline & (c) Tidak & & 5 & $9,3 \%$ \\
\hline \multicolumn{2}{|r|}{ Jumlah } & 53 & 53 & $100 \%$ \\
\hline
\end{tabular}


Dari tabel diatas dapat diketahui bahwa tentang guru memulai pelajaran dengan menyusuh siswa untuk duduk rileks/santai adalah tergolong sedang atau cukup, terbukti 51,0\% menjawab kadangkadang, kemudian baru 39,7\% menjawab ya dan 9,3\% menjawab tidak.

Guru memulai pelajaran dengan menyuruh siswa mengosongkan pikiran sesaat

\begin{tabular}{|c|l|c|c|c|}
\hline No & Alternatif Jawaban & N & F & \% \\
\hline \multirow{3}{*}{12} & (a) Ya & & 13 & $24,5 \%$ \\
& (b) Kadang-kadang & 53 & 36 & $67,9 \%$ \\
& (c) Tidak & & 4 & $7,6 \%$ \\
\hline \multicolumn{2}{|r|}{ Jumlah } & 53 & 53 & $100 \%$ \\
\hline
\end{tabular}

Dari tabel diatas dapat diketahui bahwa tentang guru memulai pelajaran dengan menyusuh siswa untuk mengosongkan pikiran untuk sesaat adalah tergolong cukup, terbukti 67,9\% menjawab kadang-kadang, kemudian baru 24,5\% menjawab ya dan 7,6 \% menjawab tidak.

Guru menyuruh menarik nafas dari hidung dan mengeluarkan dari mulut

\begin{tabular}{|c|l|c|c|c|}
\hline No & Alternatif Jawaban & N & F & \% \\
\hline \multirow{3}{*}{13} & (a) Ya & & 19 & $35,9 \%$ \\
& (b) Kadang-kadang & 53 & 29 & $54,8 \%$ \\
& (c) Tidak & & 5 & $9,3 \%$ \\
\hline \multicolumn{2}{|r|}{ Jumlah } & 53 & 53 & $100 \%$ \\
\hline
\end{tabular}

Dari tabel diatas dapat diketahui bahwa tentang guru menyuruh menarik nafas dari hidung dan mengeluarkan dari mulut adalah tergolong cukup atau sedang, terbukti 54,8 \% menjawab kadangkadang, kemudian baru 35,9\% menjawab ya dan menjawab 9,3\% tidak. 


\section{Guru memberikan sugesti pada setiap tarikan nafas supaya badan} rileks/santai

\begin{tabular}{|c|l|c|c|c|}
\hline No & Alternatif Jawaban & N & F & \% \\
\hline \multirow{3}{*}{14} & (a) Ya & & 21 & $39,7 \%$ \\
& (b) Kadang-kadang & 53 & 26 & $49 \%$ \\
& (c) Tidak & & 6 & $11,3 \%$ \\
\hline \multicolumn{2}{|l|}{ Jumlah } & 53 & 53 & 100 \\
\hline
\end{tabular}

Dari tabel diatas dapat diketahui bahwa tentang guru memberikan sugesti pada setiap tarikan nafas supaya badan rileks/santai adalah tergolong cukup atau sedang, terbukti $49 \%$ menjawab kadang-kadang, kemudian baru 39,7 \% menjawab ya dan $11,3 \%$ menjawab tidak.

Guru memberikan sugesti positif

\begin{tabular}{|c|l|c|c|c|}
\hline No & Alternatif Jawaban & N & F & \% \\
\hline \multirow{3}{*}{15} & (a) Ya & & 18 & $34 \%$ \\
& (b) Kadang-kadang & 53 & 30 & $56,7 \%$ \\
& (c) Tidak & & 5 & $9,3 \%$ \\
\hline \multicolumn{2}{|c|}{ Jumlah } & 53 & 53 & $100 \%$ \\
\hline
\end{tabular}

Dari tabel diatas dapat diketahui bahwa tentang guru memberikan sugesti positif adalah tergolong cukup, terbukti 56,7\% menjawab kadang-kadang, kemudian baru $34 \%$ menjawab ya dan 9,3\% menjawab tidak.

Langkah selanjutnya adalah mencari skor dari 15 pertanyaan angket tersebut yang telah di sebarkan pada 53 responden, dengan ketentuan:

1. Jika menjawab (a) maka di beri skor nilai 3

2. Jika menjawab (b) maka di beri skor nilai 2

3. Jika menjawab (c) maka di beri skor nilai 1 
Subiyono \& Nur Hamim

Skor Angket Penerapan Metode Hypnoteaching di SMP Bina Bangsa

\begin{tabular}{|c|c|c|c|c|c|c|c|c|c|c|c|c|c|c|c|c|c|}
\hline \multirow{2}{*}{ No } & \multicolumn{15}{|c|}{ Item Pertanyaan Angket } & \multirow[t]{2}{*}{$\mathbf{J m l}$} & \multirow[t]{2}{*}{ Ket } \\
\hline & 1 & 2 & 3 & 4 & 5 & 6 & 7 & 8 & 9 & 10 & & $\begin{array}{l}1 \\
2\end{array}$ & $\begin{array}{l}1 \\
3\end{array}$ & & $\begin{array}{l}1 \\
5\end{array}$ & & \\
\hline 1 & 2 & 3 & 2 & 3 & 2 & 2 & 2 & 3 & 2 & 3 & 2 & 3 & 2 & 1 & 2 & 34 & $\mathrm{C}$ \\
\hline 2 & 3 & 3 & 3 & 2 & 2 & 3 & 2 & 2 & 3 & 2 & 3 & 2 & 1 & 2 & 2 & 35 & B \\
\hline 3 & 3 & 3 & 3 & 3 & 3 & 3 & 2 & 3 & 2 & 1 & 3 & 2 & 2 & 2 & 2 & 36 & $\mathrm{~B}$ \\
\hline 4 & 3 & 3 & 3 & 2 & 3 & 2 & 3 & 2 & 3 & 2 & 3 & 2 & 2 & 3 & 3 & 40 & $\mathrm{~B}$ \\
\hline 5 & 2 & 2 & 2 & 3 & 3 & 2 & 3 & 3 & 3 & 3 & 2 & 2 & 3 & 3 & 3 & 39 & $\mathrm{~B}$ \\
\hline 6 & 1 & 2 & 3 & 3 & 2 & 3 & 2 & 2 & 3 & 3 & 1 & 2 & 3 & 1 & 2 & 34 & $\mathrm{C}$ \\
\hline 7 & 2 & 1 & 2 & 3 & 3 & 2 & 2 & 3 & 2 & 2 & 2 & 3 & 3 & 3 & 2 & 34 & $\mathrm{C}$ \\
\hline 8 & 3 & 2 & 2 & 2 & 2 & 3 & 2 & 3 & 2 & 2 & 3 & 2 & 2 & 3 & 2 & 35 & B \\
\hline 9 & 2 & 3 & 3 & 2 & 3 & 2 & 3 & 3 & 3 & 2 & 2 & 2 & 2 & 2 & 3 & 35 & $\mathrm{~B}$ \\
\hline 10 & 3 & 3 & 2 & 3 & 3 & 2 & 3 & 2 & 3 & 3 & 3 & 2 & 2 & 2 & 2 & 38 & B \\
\hline 11 & 3 & 2 & 2 & 1 & 2 & 1 & 3 & 2 & 3 & 3 & 3 & 2 & 2 & 2 & 2 & 37 & B \\
\hline 12 & 3 & 3 & 2 & 2 & 2 & 2 & 2 & 3 & 3 & 3 & 3 & 2 & 3 & 3 & 2 & 34 & $\mathrm{C}$ \\
\hline 13 & 2 & 3 & 3 & 2 & 2 & 3 & 1 & 2 & 3 & 3 & 2 & 2 & 3 & 2 & 2 & 36 & B \\
\hline 14 & 2 & 2 & 2 & 3 & 3 & 2 & 2 & 2 & 3 & 2 & 2 & 2 & 1 & 3 & 3 & 33 & $\mathrm{C}$ \\
\hline 15 & 2 & 3 & 3 & 2 & 3 & 2 & 1 & 2 & 3 & 3 & 1 & 2 & 2 & 1 & 2 & 30 & $\mathrm{C}$ \\
\hline 16 & 2 & 3 & 3 & 3 & 2 & 3 & 2 & 3 & 2 & 3 & 2 & 2 & 2 & 3 & 3 & 36 & B \\
\hline 17 & 3 & 3 & 2 & 2 & 2 & 2 & 3 & 3 & 2 & 2 & 2 & 1 & 3 & 3 & 2 & 36 & B \\
\hline 18 & 2 & 2 & 1 & 3 & 3 & 2 & 3 & 2 & 3 & 2 & 3 & 2 & 2 & 2 & 2 & 35 & $B$ \\
\hline 19 & 2 & 2 & 3 & 2 & 3 & 2 & 2 & 2 & 2 & 3 & 2 & 2 & 3 & 2 & 2 & 36 & B \\
\hline 20 & 2 & 1 & 2 & 2 & 2 & 3 & 2 & 3 & 3 & 2 & 2 & 3 & 3 & 2 & 2 & 34 & $\mathrm{C}$ \\
\hline 21 & 2 & 2 & 2 & 1 & 2 & 3 & 3 & 3 & 2 & 3 & 3 & 1 & 2 & 2 & 2 & 33 & $\mathrm{C}$ \\
\hline 22 & 3 & 2 & 2 & 2 & 2 & 2 & 3 & 2 & 3 & 2 & 3 & 2 & 3 & 2 & 1 & 35 & B \\
\hline 23 & 1 & 2 & 3 & 2 & 3 & 2 & 3 & 3 & 2 & 3 & 2 & 3 & 3 & 3 & 3 & 35 & B \\
\hline 24 & 3 & 2 & 2 & 3 & 3 & 3 & 2 & 2 & 2 & 2 & 1 & 3 & 2 & 1 & 3 & 35 & B \\
\hline 25 & 3 & 3 & 3 & 2 & 3 & 2 & 2 & 2 & 3 & 2 & 3 & 2 & 3 & 3 & 2 & 37 & B \\
\hline 26 & 2 & 2 & 2 & 2 & 2 & 3 & 2 & 2 & 3 & 3 & 3 & 3 & 3 & 2 & 3 & 38 & B \\
\hline 27 & 2 & 3 & 2 & 3 & 3 & 3 & 2 & 2 & 3 & 3 & 2 & 3 & 2 & 3 & 3 & 36 & B \\
\hline 28 & 2 & 2 & 3 & 3 & 2 & 2 & 2 & 2 & 2 & 3 & 3 & 2 & 3 & 2 & 3 & 39 & B \\
\hline 29 & 2 & 2 & 2 & 2 & 2 & 3 & 3 & 3 & 2 & 2 & 2 & 3 & 2 & 3 & 2 & 34 & $\mathrm{C}$ \\
\hline 30 & 2 & 1 & 3 & 2 & 3 & 3 & 3 & 3 & 3 & 2 & 2 & 1 & 2 & 2 & 2 & 32 & $\mathrm{C}$ \\
\hline
\end{tabular}




\begin{tabular}{|l|l|l|l|l|l|l|l|l|l|l|l|l|l|l|l|l|l|}
\hline 31 & 2 & 2 & 3 & 3 & 2 & 2 & 2 & 1 & 2 & 3 & 3 & 3 & 1 & 2 & 2 & 37 & $\mathrm{~B}$ \\
\hline 32 & 2 & 2 & 2 & 2 & 3 & 3 & 3 & 2 & 3 & 2 & 2 & 2 & 3 & 2 & 3 & 35 & $\mathrm{~B}$ \\
\hline 33 & 3 & 3 & 2 & 3 & 3 & 2 & 2 & 2 & 2 & 2 & 2 & 2 & 2 & 2 & 2 & 35 & $\mathrm{~B}$ \\
\hline 34 & 3 & 3 & 2 & 3 & 1 & 2 & 2 & 3 & 3 & 3 & 1 & 3 & 2 & 3 & 2 & 35 & $\mathrm{~B}$ \\
\hline 35 & 2 & 2 & 3 & 2 & 2 & 3 & 3 & 2 & 2 & 2 & 2 & 2 & 2 & 3 & 3 & 35 & $\mathrm{~B}$ \\
\hline 36 & 3 & 2 & 2 & 3 & 2 & 2 & 3 & 2 & 2 & 3 & 3 & 2 & 2 & 3 & 1 & 36 & $\mathrm{~B}$ \\
\hline 37 & 2 & 2 & 3 & 2 & 2 & 2 & 3 & 2 & 3 & 2 & 2 & 3 & 2 & 2 & 2 & 34 & $\mathrm{C}$ \\
\hline 38 & 3 & 1 & 2 & 2 & 2 & 1 & 2 & 3 & 3 & 3 & 3 & 1 & 2 & 3 & 2 & 36 & $\mathrm{~B}$ \\
\hline 39 & 3 & 3 & 2 & 3 & 3 & 3 & 1 & 2 & 2 & 3 & 2 & 2 & 3 & 2 & 2 & 32 & $\mathrm{C}$ \\
\hline 40 & 2 & 3 & 3 & 1 & 2 & 2 & 2 & 1 & 2 & 2 & 2 & 2 & 3 & 1 & 2 & 33 & $\mathrm{C}$ \\
\hline 41 & 1 & 3 & 1 & 2 & 3 & 1 & 3 & 3 & 3 & 2 & 2 & 2 & 2 & 3 & 3 & 32 & $\mathrm{C}$ \\
\hline 42 & 3 & 2 & 3 & 3 & 3 & 3 & 2 & 2 & 1 & 3 & 2 & 2 & 1 & 2 & 1 & 32 & $\mathrm{C}$ \\
\hline 43 & 2 & 2 & 3 & 2 & 1 & 2 & 1 & 2 & 3 & 1 & 3 & 2 & 3 & 1 & 2 & 33 & $\mathrm{C}$ \\
\hline 44 & 2 & 3 & 3 & 3 & 3 & 3 & 3 & 3 & 3 & 3 & 2 & 2 & 2 & 2 & 2 & 31 & $\mathrm{C}$ \\
\hline 45 & 3 & 2 & 3 & 2 & 3 & 2 & 3 & 2 & 2 & 3 & 3 & 2 & 3 & 3 & 3 & 41 & $\mathrm{~B}$ \\
\hline 46 & 2 & 3 & 3 & 2 & 2 & 3 & 2 & 3 & 3 & 2 & 3 & 3 & 3 & 2 & 3 & 36 & $\mathrm{~B}$ \\
\hline 47 & 3 & 3 & 2 & 2 & 3 & 2 & 3 & 2 & 2 & 3 & 3 & 2 & 3 & 3 & 3 & 40 & $\mathrm{~B}$ \\
\hline 48 & 2 & 2 & 2 & 3 & 2 & 3 & 2 & 3 & 3 & 2 & 2 & 2 & 2 & 3 & 2 & 34 & $\mathrm{C}$ \\
\hline 49 & 3 & 2 & 3 & 3 & 3 & 3 & 3 & 3 & 3 & 3 & 2 & 2 & 2 & 2 & 2 & 38 & $\mathrm{~B}$ \\
\hline 50 & 3 & 3 & 3 & 2 & 3 & 3 & 3 & 2 & 2 & 3 & 2 & 2 & 2 & 2 & 3 & 41 & $\mathrm{~B}$ \\
\hline 51 & 2 & 3 & 2 & 2 & 3 & 2 & 2 & 3 & 3 & 2 & 3 & 2 & 1 & 3 & 3 & 35 & $\mathrm{~B}$ \\
\hline 52 & 3 & 2 & 3 & 2 & 2 & 2 & 3 & 3 & 2 & 3 & 1 & 3 & 2 & 3 & 2 & 36 & $\mathrm{~B}$ \\
\hline 53 & 3 & 3 & 2 & 3 & 3 & 3 & 3 & 2 & 2 & 2 & 3 & 2 & 2 & 2 & 1 & 36 & $\mathrm{~B}$ \\
\hline & & & & & \multicolumn{7}{|l}{ Jumlah Skor Semuanya } & & \\
& & & & & & & & & & & & \\
\hline
\end{tabular}

\section{Prestasi Belajar Siswa}

Data tentang prestasi belajar siswa adalah di peroleh dari hasil ulangan harian siswa pada mata pelajaran PAI pada 53 responden, yaitu sebagai berikut: 
Subiyono \& Nur Hamim

\begin{tabular}{|c|c|c|c|}
\hline NO & NAMA SISWA & KELAS & $\begin{array}{c}\text { NILAI } \\
\text { ULANGAN }\end{array}$ \\
\hline 1 & Ana Dewi Sinta & $\begin{array}{l}\text { VII A } \\
\end{array}$ & 8 \\
\hline 2 & Arul Eka Prastya & VII A & 7 \\
\hline 3 & Firman Maulana & VII A & 7 \\
\hline 4 & Ndaru Murti & VII A & 8 \\
\hline 5 & $\begin{array}{l}\text { Alfarel Lingga Setyana } \\
\text { P. }\end{array}$ & VII B & 9 \\
\hline 6 & Bagas Setiawan & VII B & 6 \\
\hline 7 & Muh. Hafidz Ervani & VII B & 7 \\
\hline 8 & $\begin{array}{l}\text { Muh. Yayang Putra } \\
\text { Pratama }\end{array}$ & VII B & 8 \\
\hline 9 & Alifiatul Fauziah & VII C & 8 \\
\hline 10 & Arika Rahmawati & VII C & 7 \\
\hline 11 & $\begin{array}{ll}\text { Brenda } & \text { Clarita } \\
\text { Nevianing } & \end{array}$ & VII C & 7 \\
\hline 12 & Moh. Ari Setiawan & VII C & 7 \\
\hline 13 & Bagus Putra Pratama & VII D & 6 \\
\hline 14 & Devi Permatasari & VII D & 9 \\
\hline 15 & Dian Melinda Yuliatin & VII D & 8 \\
\hline 16 & Euis Anisa & VII D & 9 \\
\hline 17 & Melani Beti Cahyati & VII E & 7 \\
\hline 18 & Siti Nur Hanifah & VII E & 8 \\
\hline 19 & Risqi Faridz Ardiansyah & VII E & 9 \\
\hline 20 & M. Firman Amirullah & VII E & 6 \\
\hline 21 & Dian Putitasari & VIII A & 7 \\
\hline 22 & Moh. Bayu Ardiansyah & VIII A & 7 \\
\hline 23 & Novia Dwi Anggraini & VIII A & 7 \\
\hline 24 & Mishawanti & VIII A & 6 \\
\hline 25 & Nur Aulia Rahmawati & VIII A & 6 \\
\hline 26 & Rafi Dwi Ardianto & VIII A & 8 \\
\hline 27 & Cindy Kartika Akhadilla & VIII B & 7 \\
\hline 28 & Ade Hardianto & VIII B & 6 \\
\hline 29 & Dian Pratiwi Anwar & VIII B & 8 \\
\hline
\end{tabular}




\begin{tabular}{|l|l|c|c|}
\hline 30 & Bidayatul Hidayah & VIII C & 7 \\
\hline 31 & Alwin Nofrial Nurwanto & VIII C & 7 \\
\hline 32 & Oky Sandi Prasetiyo & VIII C & 8 \\
\hline 33 & Moh. Ari Ardianto & VIII D & 9 \\
\hline 34 & Nikko Nur Pratama & VIII D & 9 \\
\hline 35 & Moh. Saichuddin & VIII D & 8 \\
\hline 36 & Nita Dwi Ningtias & VIII E & 7 \\
\hline 37 & Rahmad Dwi Sanjaya & VIII E & 7 \\
\hline 38 & Syahrul Nafiuddin & VIII E & 6 \\
\hline 39 & Ayu Puspita Putri & IX A & 6 \\
\hline 40 & Gusti Ayu Yasinta & IX A & 7 \\
\hline 41 & Edo Dwi Prasetyo & IX A & 7 \\
\hline 42 & Sadewa bagus & IX B & 8 \\
\hline 43 & Widya Ayu Pratama & IX B & 8 \\
\hline 44 & Yuli Dwi Setiawan & IX B & 7 \\
\hline 45 & Bermahani Sukma & IX C & 7 \\
\hline 46 & Dewi Megawati & IX C & 6 \\
\hline 47 & Gangsar Maulana & IX C & 6 \\
\hline 48 & Indah Sari & IX D & 7 \\
\hline 49 & Maliatus Sa'dia & IX D & 8 \\
\hline 50 & Eka Febriani & IX D & 7 \\
\hline 51 & Ike Prastika & IX E & 7 \\
\hline 52 & Siti Yunitasari & IX E & 7 \\
\hline 53 & Fidyawati Dian Permana & IX E & 9 \\
\hline & \multicolumn{2}{|c|}{ JUMLAH SEMUANYA ( y ) } & 388 \\
\hline
\end{tabular}

\section{E. Analisis Data}

\section{Analisis Penerapan Metode Hypnoteaching}

Setelah penulis menyajikan data tentang penerapan metode hypnoteaching, maka selanjutnya penulis akan menganalisis data tersebut, yaitu dengan menggunakan rumus prosentase sebagai berikut : 


$$
P=\frac{f}{N} \times 100 \%
$$

Keterangan :

$\mathrm{P} \quad=$ Angka prosentase

$\mathrm{F} \quad=$ Frekuensi jawaban yang akan dicari prosentasenya

$\mathrm{N}$ = Jumlah frekuensi atau sampel penelitian

Tetapi sebelumnya penulis mengelompokkan nilai variabel X ( penerapan metode hypnoteaching) kedalam kategori-kategori ( baik, cukup dan kurang), yaitu dengan menggunakan rumus :

$$
R=H-L+1
$$

Keterangan :

$\mathrm{R} \quad=$ Angka kategori

$\mathrm{H}=$ Nilai pertanyaan angket (tertinggi dan terendah)

$\mathrm{L} \quad=$ Jumlah pertanyaan angket

Adapun langkah-langkahnya adalah sebagai berikut :

Langkah 1 : Mencari nilai tertinggi dan nilai terendah, yaitu :

$$
\begin{aligned}
& N t=3 \times 15=45 \rightarrow 45-15+1=31 \\
& N r=1 \times 15=15 \rightarrow 15-15+1=1
\end{aligned}
$$

Langkah 2: Mencari interval nilai kategorinya, yaitu :

$$
\text { In }=\frac{31}{3}=10
$$

Langkah 3 : Menentukan kategori-kategorinya, yaitu :

$$
\begin{aligned}
& \text { Baik } \rightarrow \text { Interval Nilai } 35-45 \\
& \text { Cukup } \rightarrow \text { Interval Nilai } 25-34 \\
& \text { Kurang } \rightarrow \text { Interval Nilai } 15-24
\end{aligned}
$$

Selanjutnya berkenaan dengan kepentingan interpretasi sesuai dengan rumusan masalah dan tujuan penelitian, maka berikut ini akan disajikan distribusi frekuensi beserta prosentase yang diperoleh dari perhitungan data pada tabel berikut : 
Distribusi Frekuensi dan Prosentase Data

Mengenai Penerapan Metode Hypnoteaching

\begin{tabular}{|c|c|c|c|c|c|}
\hline No & Interval Nilai & Kategori & N & F & Prosentase \\
\hline 1 & $35-45$ & Baik & & 35 & $66 \%$ \\
2 & $25-34$ & Cukup & 53 & 18 & $34 \%$ \\
3 & $15-24$ & Kurang & & 0 & $0 \%$ \\
\hline \multicolumn{2}{|r|}{ Jumlah } & $\mathbf{5 3}$ & $\mathbf{5 3}$ & $\mathbf{1 0 0} \%$ \\
\hline
\end{tabular}

Dari tabel diatas dapat di ketahui bahwa mengenai rincian prosentase tentang variabel X ( penerapan metode hypnoteaching ) di SMP Bina Bangsa Surabaya adalah sebagai berikut :

$$
\begin{gathered}
P=\frac{f}{N} \times 100 \% \\
\text { Baik }=\frac{35 \times 100}{53}=66 \% \\
\text { Cukup }=\frac{18 \times 100}{53}=34 \%
\end{gathered}
$$

Dari rincian prosentase diatas dapat diketahui bahwa prosentase tertinggi mengenai variabel $\mathrm{X}$ (penerapan metode hypnoteaching) di SMP Bina Bangsa Surabaya adalah $66 \%$. Kemudian untuk mencari nilai dari variabel X ( penerapan metode hypnoteaching ), maka hasil dari prosentase tertinggi ( $66 \%$ ) harus dikonsultasikan dengan interpretasi prosentase dari Suharsimi Arikunto, yaitu sebagai berikut:
a) $76 \%-100 \%$
$=$ Baik
b) $56 \%-75 \%$
$=$ Cukup
c) $40 \%-55 \%$
= Kurang
d) Kurang dari $40 \%=$ Tidak Baik

Ternyata hasil dari prosentase tertinggi ( $66 \%$ ) adalah berada pada interval $56 \%$ - $75 \%$ yang berarti cukup. Jadi mengenai nilai variabel X ( penerapan metode hypnoteaching) di SMP Bina Bangsa tergolong cukup. 


\section{Analisis Prestasi Belajar}

Dari nilai ulangan pada 53 responden yang telah dipaparkan diatas, kemudian dicari rata-rata nilai ulangan tersebut dengan menggunakan rumus sebagai berikut:

$$
\begin{aligned}
M y & =\frac{\Sigma y}{N} \\
& =\frac{388}{53} \\
& =7,3
\end{aligned}
$$

Selanjutnya dari hasil rata-rata diatas $(7,3)$, kemudian dikonsultasikan pada kategori nilai ulangan yang ada dibawah ini :

\begin{tabular}{|c|c|c|c|}
\hline NILAI & KATEGORI & NILAI & KATEGORI \\
\hline \hline 10 & Istimewa & 5 & Hampir \\
\hline 9 & Sangat baik & 4 & Kurang \\
\hline 8 & Baik & 3 & Kurang sekali \\
\hline 7 & Cukup Baik & 2 & Buruk \\
\hline 6 & Cukup & 1 & Buruk sekali \\
\hline
\end{tabular}

Hasil Rata-rata dari ulangan harian siswa $(7,3)$ adalah berada pada interval nilai 7-8 yang artinya tergolong kategori baik. Jadi, prestasi belajar siswa di SMP Bina Bangsa Surabaya adalah tergolong baik.

3. Analisis tentang Ada atau Tidaknya Pengaruh Penerapan Metode Hypnoteaching terhadap Prestasi Belajar Siswa di SMP Bina Bangsa Surabaya

Untuk mengetahui ada atau tidaknya pengaruh penerapan metode hypnoteaching terhadap prestasi belajar siswa di SMP Bina Bangsa Surabaya.maka penulis menggunakan analisis statistik Product Moment, yaitu dengan rumus :

$$
r_{X Y}=\frac{N \cdot \sum X Y-\left(\sum X\right)\left(\sum Y\right)}{\sqrt{\left\{N . \sum X^{2}-\left(\sum X\right)^{2}\right\}\left\{N . \sum Y^{2}-\left(\sum Y\right)^{2}\right\}}}
$$


Keterangan :

$\mathrm{r}_{\mathrm{xy}} \quad=$ Angka indeks korelasi " $\mathrm{r}$ " Product Moment

$\mathrm{N} \quad=$ Number of Cases

$\sum \mathrm{XY}=$ Jumlah hasil perkalian antara skor $\mathrm{X}$ dan skor $\mathrm{Y}$

$\sum X \quad=$ Jumlah seluruh skor $\mathrm{X}$

$\sum \mathrm{Y}=$ Jumlah seluruh skor $\mathrm{Y}$

Adapun langkah-langkah yang harus ditempuh dalam mengetahui nilai $r_{x y}$ adalah sebagai berikut :

Langkah 1: Menjumlahkan subyek penelitian, diperoleh $\mathrm{N}=53$

Langkah 2: Menjumlahkan skor variabel $X$, diperoleh $\sum X=1874$

Langkah 3: Menjumlahkan skor variabel $\mathrm{Y}$, diperoleh $\sum \mathrm{Y}=388$

Langkah 4: Mengalikan skor variabel $\mathrm{X}$ dengan skor variabel $\mathrm{Y}$ ( yaitu : $\sum X Y$ ) setelah selesai lalu dijumlahkan, di peroleh $\sum X Y=13.713$

Langkah 5: Menguadratkan skor variabel $X\left(\right.$ yaitu : $\left.X^{2}\right)$ setelah selesai lalu dijumlahkan, diperoleh $\sum X^{2}=66.560$

Langkah 6: Menguadratkan skor variabel $\mathrm{Y}$ ( yaitu : $\mathrm{Y}^{2}$ ) setelah selesai lalu dijumlahkan, diperoleh $\sum \mathrm{Y}^{2}=2.886$

Perhitungan Untuk Memperoleh Angka Indeks Korelasi (pengaruh ) Variabel X (penerapan metode hypnoteaching) terhadap Variabel Y (prestasi belajar siswa) di SMP Bina

Bangsa Surabaya

\begin{tabular}{|c|c|c|c|c|c|}
\hline Subyek & $\mathbf{X}$ & $\mathbf{Y}$ & $\mathbf{X Y}$ & $\mathbf{X}^{\mathbf{2}}$ & $\mathbf{Y}^{\mathbf{2}}$ \\
\hline 1 & 34 & 8 & 272 & 1156 & 64 \\
\hline 2 & 35 & 7 & 245 & 1225 & 49 \\
\hline 3 & 36 & 7 & 252 & 1296 & 49 \\
\hline 4 & 40 & 8 & 320 & 1600 & 64 \\
\hline 5 & 39 & 9 & 351 & 1521 & 81 \\
\hline 6 & 34 & 6 & 204 & 1156 & 36 \\
\hline 7 & 34 & 7 & 238 & 1156 & 49 \\
\hline 8 & 35 & 8 & 280 & 1225 & 64 \\
\hline 9 & 35 & 8 & 280 & 1225 & 64 \\
\hline 10 & 38 & 7 & 266 & 1444 & 49 \\
\hline
\end{tabular}


Subiyono \& Nur Hamim

\begin{tabular}{|c|c|c|c|c|c|}
\hline 11 & 37 & 7 & 259 & 1369 & 49 \\
\hline 12 & 34 & 7 & 238 & 1156 & 49 \\
\hline 13 & 36 & 6 & 216 & 1296 & 36 \\
\hline 14 & 33 & 9 & 297 & 1089 & 81 \\
\hline 15 & 30 & 8 & 240 & 900 & 64 \\
\hline 16 & 36 & 9 & 324 & 1296 & 81 \\
\hline 17 & 36 & 7 & 252 & 1296 & 49 \\
\hline 18 & 35 & 8 & 280 & 1225 & 84 \\
\hline 19 & 36 & 9 & 324 & 1296 & 81 \\
\hline 20 & 34 & 6 & 204 & 1156 & 36 \\
\hline 21 & 33 & 7 & 231 & 1089 & 49 \\
\hline 22 & 35 & 7 & 245 & 1225 & 49 \\
\hline 23 & 35 & 7 & 245 & 1225 & 49 \\
\hline 24 & 35 & 6 & 210 & 1225 & 36 \\
\hline 25 & 37 & 6 & 222 & 1369 & 36 \\
\hline 26 & 38 & 8 & 304 & 1444 & 64 \\
\hline 27 & 36 & 7 & 252 & 1296 & 49 \\
\hline 28 & 39 & 6 & 234 & 1521 & 36 \\
\hline 29 & 34 & 8 & 272 & 1156 & 64 \\
\hline 30 & 32 & 7 & 224 & 1024 & 49 \\
\hline 31 & 37 & 7 & 259 & 1369 & 49 \\
\hline 32 & 35 & 8 & 280 & 1225 & 64 \\
\hline 33 & 35 & 9 & 315 & 1225 & 81 \\
\hline 34 & 35 & 9 & 315 & 1225 & 81 \\
\hline 35 & 35 & 8 & 280 & 1225 & 64 \\
\hline 36 & 36 & 7 & 252 & 1296 & 49 \\
\hline 37 & 34 & 7 & 238 & 1156 & 49 \\
\hline 38 & 36 & 6 & 216 & 1296 & 36 \\
\hline 39 & 32 & 6 & 192 & 1024 & 36 \\
\hline 40 & 33 & 7 & 231 & 1089 & 49 \\
\hline 41 & 32 & 7 & 224 & 1024 & 49 \\
\hline 42 & 32 & 8 & 256 & 1024 & 64 \\
\hline 43 & 33 & 8 & 264 & 1089 & 64 \\
\hline 44 & 31 & 7 & 217 & 961 & 49 \\
\hline
\end{tabular}

Jurnal Pendidikan Agama Islam

Volume 02 Nomor 02 November 2013

Hal 242 - 245 
Pengaruh Metode Hypnoteaching

\begin{tabular}{|c|c|c|c|c|c|}
\hline 45 & 41 & 7 & 287 & 1681 & 49 \\
\hline 46 & 36 & 6 & 216 & 1296 & 36 \\
\hline 47 & 40 & 6 & 240 & 1600 & 36 \\
\hline 48 & 34 & 7 & 238 & 1156 & 49 \\
\hline 49 & 38 & 8 & 304 & 1444 & 64 \\
\hline 50 & 41 & 7 & 287 & 1681 & 49 \\
\hline 51 & 35 & 7 & 245 & 1225 & 49 \\
\hline 52 & 36 & 7 & 252 & 1296 & 49 \\
\hline 53 & 36 & 9 & 324 & 1296 & 81 \\
\hline \hline$\sum$ & $\mathbf{1 8 7 4}$ & $\mathbf{3 8 8}$ & $\mathbf{1 3 . 7 1 3}$ & $\mathbf{6 6 5 6 0}$ & $\mathbf{2 8 8 6}$ \\
\hline
\end{tabular}

Langkah 7: Mencari $\mathrm{r}_{\mathrm{xy}}$ dengan rumus sebagai berikut :

$$
\begin{aligned}
r_{X Y} & =\frac{N . \Sigma X Y-\left(\sum X\right)(\Sigma Y)}{\sqrt{\left\{N . \Sigma X^{2}-(\Sigma X)^{2}\right\}\left\{N . \Sigma Y^{2}-(\Sigma Y)^{2}\right\}}} \\
& =\frac{53 \times 13.713-1874 \times 388}{\sqrt{\left\{53 \times 66.560-1874^{2}\right\}\left\{53 \times 2886-388^{2}\right\}}} \\
& =\frac{726.789-727.112}{\sqrt{\{3.527 .680-3.511 .876\}\{152.958-150.544\}}} \\
& =\frac{323}{\sqrt{\{15.804\}\{2.414\}}} \\
& =\frac{323}{\sqrt{38.150 .856}} \\
& =\frac{323}{617.6637} \\
& =0,522
\end{aligned}
$$

Dari hasil perhitungan melalui rumus Product Moment diatas diperoleh hasil perhitungan $\left(\mathrm{r}_{\mathrm{xy}}\right)$ sebesar 0,522. Kemudian untuk menganalisis ada atau tidaknya pengaruh penerapan metode hypnoteaching terhadap prestasi belajar siswa di SMP Bina Bangsa Surabaya, maka hasil perhitungan $\left(\mathrm{r}_{\mathrm{xy}}\right)$ harus dikonsultasikan 
dengan hasil kritik dari "r" Product Moment, yaitu terlebih dahulu harus mencari Degree of Fredom ( df ), yaitu dengan rumus :

$$
\begin{aligned}
\mathrm{df} & =\mathrm{N}-\mathrm{Nr} \\
& =53-2 \\
& =51
\end{aligned}
$$

Dengan df sebesar 51 maka diperoleh :

1. $r_{t}$ pada taraf signifikansi $5 \%$ sebesar 0,273

2. $r_{t}$ pada taraf signifikansi $1 \%$ sebesar 0,354

Ternyata hasil perhitungan rumus $\mathrm{r}_{\mathrm{xy}}(0,522)$ adalah lebih besar dari pada hasil perhitungan tabel $\left(r_{t}\right)$, baik pada taraf signifikansi $5 \%(0,273$ ) maupun pada taraf signifikansi $1 \%(0,354)$ yang artinya hipotesis alternatif ( $\mathrm{Ha}$ ) diterima dan Hipotesis Nihil ( Ho ) ditolak, berarti terdapat pengaruh yang signifikan antara variabel $\mathrm{X}$ (penerapan metode hypnoteaching) dengan variabel Y (prestasi belajar siswa) di SMP Bina Bangsa Surabaya.

\section{F. Kesimpulan}

Penerapan metode hypnoteaching di SMP Bina Bangsa Surabaya adalah tergolong cukup. Hal ini terbukti dari hasil prosentase tertinggi (66 $\%$ ) adalah berada pada interval $56 \%$ - $75 \%$ yang berarti cukup.

Prestasi belajar siswa di SMP Bina Bangsa Surabaya adalah tergolong baik. Hal ini terbukti dari hasil rata-rata nilai ulangan siswa $(7,3)$ adalah berada pada interval nilai 7-8 yang berarti baik.

Terdapat pengaruh penerapan metode hypnoteaching terhadap prestasi belajar siswa di SMP Bina Bangsa Surabaya. Hal ini terbukti dari hasil perhitungan rumus $r_{x y}(0,522)$ adalah lebih besar dari hasil perhitungan tabel $\left(\mathrm{r}_{\mathrm{t}}\right)$ baik pada taraf signifikansi $5 \%(0,274)$ atau pada taraf signifikansi $1 \%(0,354)$ yang berarti Ha diterima dan Ho ditolak dan berarti terdapat pengaruh variabel $\mathrm{X}$ terhadap variabel $\mathrm{Y}$. 


\section{DAFTAR PUSTAKA}

Anas Sujiono, 2008, Pengantar Satistik Pendidikan, (Jakarta: PT. Raja Grafindo Persada)

Departemen Agama RI, 2000, Al-Qur'an dan Terjemahannya, (Bandung: CV Penerbit Diponegoro)

Ibnu Hajar, 2011, Hypnoteaching Memaksimalkan Hasil Proses Belajarmengajar dengan Hypnoterapi, (Jojakarta: Diva Press)

James. L. Murseli, 1975, Pengajaran Berhasil, (Jakarta: Yayasan Penerbit Universitas Indonesia)

M. Uzer Ustman, 1995, Menjadi Guru Profesional, (Bandung: Remaja Rosda Karya)

Muhibbin Syah, 2004, Psikologi Belajar, (Jakarta: Raja Grafindo Persada)

Oemar Hamalik. 2003, Kurikulum dan Pembelajaran, (Jakarta: Bumi Aksara)

Suharsimi Arikunto, 2002, Prosedur Penelitian, (Jakarta: PT Rineka Cipta)

Suharsimi Arikunto, 2006, Prosedur Penelitian Suatu Pendekatan Praktik, (Edisi Revisi VI). (Jakarta: Rineka Cipta)

Syaiful Bahri Djamarah, 2002, Strategi Belajara Mengajar, (Jakarta: Rineka Cipta)

Trianto, 2007, Model-model Pembelajaran Inovatif Berorientasi Konstrutivistik, (Jakarta: Prestasi Pustaka Publisher)

UU RI No. 21. 2003, Tentang Sistem Pendidikan Nasional, (Bandung: Citra Umbara)

Yusuf Hadi Miarso, dkk., 1986, Teknologi Komunikasi Pendidikan, (Jakarta: Rajawali)

Zakiah Drajat dkk, 1996, Ilmu Pengetahuan Pendidikan Islam, (Jakarta: Bumi Aksara) 